\title{
Farklı depolama sürelerinin dolgulu yaş makarnanın bazı kalite özellikleri üzerine etkisi
}

\section{Effect of different storage periods on some quality properties of filled fresh pasta}

\author{
Tekmile CANKURTARAN ${ }^{1}$ iD, Nermin BiLGiçLi ${ }^{1 *}$ iD \\ ${ }^{1}$ Necmettin Erbakan Üniversitesi, Mühendislik ve Mimarlık Fakültesi, Gıda Mühendisliği Bölümü
}

\section{To cite this article:}

Cankurtaran, T. \& Bilgiçli, N. (2019). Farklı depolama sürelerinin dolgulu yaş makarnanın bazı kalite özellikleri üzerine etkisi. Harran Tarım ve Gıda Bilimleri Dergisi, 23(4): 451462.

DOI: 10.29050/harranziraat.533085

Address for Correspondence: Nermin BILGiÇLi

e-mail:

nerminbilgicli@erbakan.edu.tr

Received Date:

27.02.2019

Accepted Date:

01.11.2019

(C) Copyright 2018 by Harran University Faculty of Agriculture. Available on-line at www.dergipark.gov.tr/harranziraat

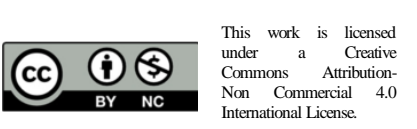

öz

Bu çalışmada, değirmencilik yan ürünleri olan buğday kepeği (BK) ve buğday ruşeymi (BR) nin dolgusuz ve dolgulu yaş makarna üretiminde kullanımının depolama süresince makarnaların bazı fiziksel, kimyasal, mikrobiyolojik ve duyusal özellikleri üzerine etkisi araştırılmıştır. Bu amaçla \%5, 10, 15 ve 20 (w/w) oranlarında BK ve BR, buğday unu ile yer değiştirilerek dolgusuz ve dolgulu yaş makarna üretiminde kullanılmış, elde edilen yaş makarna örnekleri modifiye atmosfer paketleme (MAP) uygulanarak 30 gün $+4{ }^{\circ} \mathrm{C}$ 'de depolanmıştır. BR ilaveli makarna örnekleri, BK ilaveli olanlara göre daha düşük ağırlık artışı ve suya geçen kuru madde miktarı (SGMM) vermiştir. Artan oranlarda BK ya da BR kullanımı, ağılık ve hacim artışı ile SGMM değerlerini yükseltmiştir. Depolama süresince dolgusuz ve dolgulu yaş makarnaların ağırık artışı ve hacim artışı değerlerinde istatistiki bir farklılık gözlenmezken; SGMM de artış, antioksidan aktivite ve fitik asit miktarlarında düşüş belirlenmiştir. MAP uygulanmış yaş makarna örneklerinin normal paketlenmiş makarna örneklerine göre mikrobiyolojik kalitelerinin çok daha üstün olduğu saptanmıştır. Yaş makarna üretiminde en iyi sonuç sırasıyla \%10 BK ve \%15 BR ilavesi ile elde edilmiştir.

Anahtar Kelimeler: Buğday kepeği, Buğday ruşeymi, Depolama, Dolgulu yaş makarna, MAP

\section{ABSTRACT}

In this study, the effects of wheat bran (WB) and wheat germ (WG), which are milling byproducts, on some physical, chemical, microbiological and sensory properties of filled and unfilled fresh pasta during storage period were investigated. For this purpose, different ratios $(5,10,15$ and $20 \%(w / w))$ of WB and WG were used in the production of filled and unfilled fresh pasta by replacing with wheat flour. Fresh pasta samples were stored at $+4^{\circ} \mathrm{C}$ for 30 days using modified atmosphere packaging (MAP). Fresh pasta samples with WG had lower weight increase and cooking loss values than the samples containing WB. Increasing amount of WB or WG raised weight increase, volume increase and cooking loss values. During storage periods, WB and WG incorporation into filled and unfilled fresh pasta increased cooking loss and decreased antioxidant activity and phytic acid. There were no significant differences in the weight increase and volume increase values of filled and unfilled fresh pasta samples during storage period. The microbiological qualities of MAP-applied fresh pasta samples were significantly higher than normal packaged pasta samples. In general, the best results were obtained when WB and WG were added to the fresh pasta at $10 \%$ and $15 \%$, respectively.

Key Words: Wheat bran, Wheat germ, Storage, Fresh filled pasta, MAP.

\section{Giriş}

Makarna, kuru ve yaş makarna olmak üzere iki büyük grupta sınıflandırımaktadır (Tazrart ve ark.,
2016). Yüksek su içeriğine sahip dolgulu yaş makarna, bir çift hamur şeridinin sebze, peynir veya et ürünleri gibi uygun dolgu materyali ile bir araya getirilmesi sonucu elde edilen geleneksel 
İtalyan ev yapımı makarnadan geliştirilen endüstriyel üründür. Tortelli ve ravioli gibi farklı şekilleri mevcut olan dolgulu yaş makarnanın hamur yaprağı yaklaşık \%35 (w/w) su içeriğine sahiptir. Bu özelliği ile $\% 11,5$ (w/w) nem miktarına sahip klasik kuru makarnadan ayrılmaktadır. Hamur ve dolgu materyalinin yüksek su aktivitesi mikrobiyal aktiviteyi arttırarak yaş makarnaların raf ömrünü önemli düzeyde sınırlandırmaktadır (de Cindio ve ark., 2001).

Pastörizasyon, endüstriyel yaş makarna üretiminde mikrobiyal yükün azaltmasının yanı sıra ürün kalitesinin ve besinsel özelliklerinin korunmasında önemli bir işlemdir. Birçok gıda ürününde olduğu gibi yaş makarna örneklerinde uygulanan bu ısıl işlem mikrobiyal yükü sınırlandırmakla birlikte, ürün rengini (Zardetto ve Dalla Rosa, 2007) ve tekstür özelliklerini iyileştirmekte (Alamprese ve ark., 2005), nişasta jelatinizasyonunu artırmakta (Zardetto ve ark., 2002) ve pişirme sırasında pişme özelliklerini geliştirmektedir (Zuliani, 1998; Zardetto ve ark., 2002; Alamprese ve ark., 2008). Ayrica MAP uygulaması ile raf ömrü daha da artırılabilmektedir.

MAP, ambalajın içerisindeki gıdanın etrafını saran hava bileşiminin başka bir gazla değiştirilmesine dayanan paketleme sistemidir. Ticari MAP' da kullanılan temel iki gaz azot $\left(\mathrm{N}_{2}\right)$ ve karbon dioksittir $\left(\mathrm{CO}_{2}\right) \cdot \mathrm{CO}_{2}$ hem bakteriyostatik hem de fungistatik özelliğe sahiptir (Daniels ve ark., 1985). Dolgu gazı olarak kullanılan nötr karakterdeki $\mathrm{N}_{2}$ ambalajda oluşabilecek çökmeleri engelleyerek ürünün tazeliğini korumakta ve gıda güvenliğini artırmaktadır.

MAP düşük su aktivitesi ve düşük depolama sıcaklığı ile birlikte uygulandığında mikrobiyal gelişimi etkili bir şekilde önlemektedir (Northolt ve Bullerman, 1982). Ürün özelliklerine bağlı olarak dolgulu yaş makarnaların paketlenmesinde \%25-40 oranında $\mathrm{CO}_{2}$ kullanılmaktadır. Castelvetri (1991) dolgulu yaş makarna muhafazasında \%30'un üzerinde $\mathrm{CO}_{2}$ kullanılmasının ürünün raf ömrünü 30 günün üzerine çıkardığını bildirmiştir. Diğer taraftan \%70'in üzerinde $\mathrm{N}_{2}$ kullanılması makarna örneklerinin ortam havasındaki $\mathrm{CO}_{2}{ }^{\prime} \mathrm{i}$ absorbe etmesinden kaynaklı paketlerin çökmesini önlemektedir.

Dünya genelinde değirmencilik sektörünün yan ürünü olarak ortaya çıkan BK ve BR esas olarak hayvan yemlerinde kullanılırken, çok küçük miktarı gıda amaçlı kullanılmaktadır (Ge ve ark., 2001; Apprich ve ark., 2014). BK lif, B grubu vitaminler ve biyoaktif maddelerce zengin oluşuyla pek çok gıda formülasyonunda kullanılmaktadır (Reisinger ve ark., 2013). Buğday kepeğinin perikarp kısmı iç ve dış perikarp olmak üzere iki kısımdan meydana gelmekte olup fenolik asit ve diyet lifi bakımından zengindir (Apprich ve ark., 2014). Testa kısmında baskın olarak fenolik özellikte biyoaktif bileşenler yer alırken (Rebolleda ve ark., 2013) endosperme en yakın kısım olan aleuron tabakasında proteinler, biyoaktif bileşenler, fitik asit, antioksidanlar, vitaminler ve mineraller yer almaktadır (Javed ve ark., 2012). BK' nin mineral içeriği oldukça yüksektir. Kaur ve ark. (2012), BK (\%15) kullanarak ürettikleri makarnaların duyusal özelliklerinin kabul edilebilir olduğunu, bununla birlikte ede edilen makarnaların daha koyu renkte olup, pişme sırasında su absorbsiyonun arttığını bildirmişlerdir. Benzer bir çalışmada, BK oranının \%20‘nin üzerine çıkarılması ile pişmiş makarnalarda yapının zayıfladığı ve yapışkanlığın arttığı tespit edilmiştir (Wojtowicz ve Moscicki, 2011). Sobota ve ark., (2015) BK kullanımının makarnaların protein, yağ, kül ve toplam diyet lifi miktarında artış ile birlikte makarnanın renginde koyulaşmaya yol açtığını ifade etmişlerdir.

BR ağırlıklı olarak albüminler ve globülinlerden oluşan yüksek protein içeriğine (> \%20) sahiptir (Gómez ve ark., 2012). İçerdiği proteinlerin biyolojik değeri, hayvansal kaynaklı proteinlere yakındır. Yapılan birçok çalışmada BR ve ürünlerinin antikanserojenik özelliğe sahip olduğu bilimsel olarak ortaya konmuştur. Ayrıca tokoferollerin, B grubu vitaminlerinin, doymamıs yağ asitlerinin (özelliklede oleik, linoleik ve $\alpha$ linoleik asit), fonksiyonel özellikli fitokimyasalların (flavonoidler ve steroller) ve esansiyel aminoasitlerin oldukça zengin bir kaynağıdır (Demir ve Elgün, 2014). Yüksek antioksidan etkiye 
sahip BR' nin (Zhokhov ve ark., 2010) insanlardan izole edilen bifidobakterinin gelişmesi üzerine de olumlu etkisi olduğu saptanmıştır (Arrigoni ve ark., 2002). Aravind ve ark. (2012), formülasyonunda $B K$ ve $B R$ kullandıkları makarnaların yüksek antioksidan kapasitesine ve yüksek diyet lifi miktarına sahip olduğunu bildirmişlerdir. BR' nin, kek üretiminde hamur yoğunluğunu ve iç renkte sarılığı arttırdığı (Majzoobi ve ark., 2012) ve elde dilen keklerin mineral madde miktarı, kül, yağ, protein içeriğinde artış sağladığı (Bilgiçli ve Levent, 2013) yapılan çalışmalar ile ortaya çıkarılmıştır.

Bu çalışmada farklı oranlarda (\%5, 10, 15 ve 20) $B K$ ve $B R$ ilave edilerek fonksiyonel özellikleri geliştirilmiş dolgusuz ve dolgulu yaş makarna üretilmiştir. Yüksek su içeriğinden dolayı kısa olan raf ömrünü uzatmak amacıyla pastörizasyon ve MAP uygulamaları gerçekleştirilerek, 30 günlük depolama süresi boyunca bazı fiziksel, kimyasal, duyusal ve mikrobiyolojik özelliklerde meydana gelen değişiklikler belirlenmiştir.

\section{Materyal ve Metot}

\section{Materyal}

Dolgusuz ve dolgulu yaş makarna üretimi sırasında kullanılan buğday unu, BK ve BR'i Konya ilinde faaliyet gösteren bir un fabrikasından, dolgu materyalinin hazırlanmasında kullanılan peynirler (lor peyniri ve krem peyniri) ve ayçiçek yağı Konya' daki yerel marketlerden temin edilmiştir. $B K$ ve $B R$ çekiçli değirmende öğütülerek $(<500$ $\mu \mathrm{m})$ depolanmışlardır.

\section{Metot}

\section{Dolgu materyalinin hazırlanması}

Dolgu materyali $1 \mathrm{~kg}$ lor peyniri, $250 \mathrm{~g}$ krem peyniri, $25 \mathrm{ml}$ ayçiçek yağı ve $30 \mathrm{~g}$ un homojen bir karışım elde edilinceye kadar mikserde karıştırılarak (Hobart N50, Canada Inc., North York, Ontario, Canada) hazırlanmıştır.

\section{Dolgusuz ve dolgulu yaş makarna üretimi}

Kontrol dolgulu yaş makarna üretiminde $1 \mathrm{~kg}$ un esasına göre $100 \mathrm{~g}$ yumurta, $230 \mathrm{~g}$ su kullanılmıştır. Tüm bileşenler tam sıvı hidratasyonu sağlanana kadar pilot makarna ünitesinin (La Monferrina, İtalya) yoğurucu kısmında karıştııılmıştır. Karıştırma işleminin ardından inceltilen hamur ravyoli kalıbından (48x48 mm ebatlarında) geçirilerek dolgu malzemesi (\%30 dolgu materyali) ile şekillendirilmiştir. Makarna formülasyonlarında un ile yer değiştirme esasına göre \%5, 10, 15 ve 20 oranında BK ve BR ayrı ayrı kullanılmıştır. Makarna örneklerinin hazırlanmasında kullanılan su miktarı ön denemeler ile belirlenmiş olup 235$300 \mathrm{ml}$ arasında değişmiştir. Ayrıca yaş makarnalar dolgu materyali ilave edilmeden dolgusuz olarak da üretilmiştir. Deneme deseni Çizelge 1 de verilmiştir. Çalışma deneme desenine göre iki tekerrürlü olarak yürütülmüştür.

Dolgusuz ve dolgulu yaş makarna örneklerinin pastörizasyonu

Dolgusuz ve dolgulu yaş makarna örneklerinin pastörizasyon işlemi için pastörizasyon ünitesi (Pama Macchine, PS150, İtalya) kullanılmıştır. Ürün, taşıyıcı bant üzerinden verilerek 9 dakika boyunca sıcaklığı $91{ }^{\circ} \mathrm{C}$ olan buhar enjeksiyonu ile pastörize edilmiştir. Pastörizasyon sonrası aynı cihazda soğutma işlemi uygulanmış ve örnekler oda sıcaklığına soğutulmuştur.

Dolgusuz ve dolgulu yaş makarna örneklerinin paketlenmesi

Pastörize edilen örnekler $\% 50-\% 50 \mathrm{CO}_{2}-\mathrm{N}_{2}$ gaz karışımı ile MAP cihazı (Apack-MAP25, Apack, Türkiye) kullanılarak modifiye atmosferde paketlenmiştir. MAP'nin yanı sıra normal paketleme işlemi de uygulanmıştır. MAP uygulaması sırasında ürünü deformasyonlara karşı korumak amacı ile $210 \times 315 \mathrm{~mm}$ ebatlarında tabak formlu ambalaj malzemesi kullanılmış ve tabakların içine yaklaşık 250-300 gram yaş makarna örneği konulmuştur. Normal paketleme işleminde ambalaj materyali olarak polietilen poşet kullanılmış ve analizlerde kullanılıncaya kadar ağzı kapalı şekilde muhafaza edilmiştir. Paketlenen dolgusuz ve dolgulu yaş makarna örnekleri $+4^{\circ} \mathrm{C}^{\prime}$ de 30 gün süre ile depolanmış ve 
depolama süresince her 10 günde bir bazı fiziksel (pişme özellikleri ve sıkılık), kimyasal (fitik asit, antioksidan aktivite ve toplam fenolik madde), mikrobiyolojik ve duyusal analizler yapılmıştır.

Çizelge 1. Yaş makarna üretiminde kullanılan deneme deseni

Table 1. The trial design for fresh pasta production

\begin{tabular}{|c|c|c|c|c|c|}
\hline $\begin{array}{l}\text { Katkı çeşidi } \\
\text { Additive type }\end{array}$ & $\begin{array}{c}\text { Katkı oranı (\%) } \\
\text { Additive ratio (\%) }\end{array}$ & $\begin{array}{c}\text { Depolama süresi } \\
\text { (gün) } \\
\text { Storage period } \\
\text { (day) }\end{array}$ & $\begin{array}{l}\text { Katkı çeşidi } \\
\text { Additive type }\end{array}$ & $\begin{array}{c}\text { Katkı oranı (\%) } \\
\text { Additive ratio (\%) }\end{array}$ & $\begin{array}{l}\text { Depolama süresi } \\
\text { (gün) } \\
\text { Storage period } \\
\text { (day) }\end{array}$ \\
\hline \multirow{20}{*}{$\begin{array}{l}\text { Buğday kepeği } \\
\text { Wheat bran }\end{array}$} & \multirow{4}{*}{0} & 0 & \multirow{20}{*}{$\begin{array}{c}\text { Buğday ruşeymi } \\
\text { Wheat germ }\end{array}$} & \multirow{4}{*}{0} & 0 \\
\hline & & 10 & & & 10 \\
\hline & & 20 & & & 20 \\
\hline & & 30 & & & 30 \\
\hline & \multirow{4}{*}{5} & 0 & & \multirow{4}{*}{5} & 0 \\
\hline & & 10 & & & 10 \\
\hline & & 20 & & & 20 \\
\hline & & 30 & & & 30 \\
\hline & \multirow{4}{*}{10} & 0 & & \multirow{4}{*}{10} & 0 \\
\hline & & 10 & & & 10 \\
\hline & & 20 & & & 20 \\
\hline & & 30 & & & 30 \\
\hline & \multirow{4}{*}{15} & 0 & & \multirow{4}{*}{15} & 0 \\
\hline & & 10 & & & 10 \\
\hline & & 20 & & & 20 \\
\hline & & 30 & & & 30 \\
\hline & \multirow{4}{*}{20} & 0 & & \multirow{4}{*}{20} & 0 \\
\hline & & 10 & & & 10 \\
\hline & & 20 & & & 20 \\
\hline & & 30 & & & 30 \\
\hline
\end{tabular}

Hem dolgulu hem de dolgusuz yaş makarna örneklerinin üretiminde $(2 \times 5 \times 4)$ x 2 faktöriyel desen kullanılmıştır. (2 $\times 5 \times 4) \times$ 2 factorial design were used for both filled and unfilled pasta production.

\section{Pişirme testleri}

Yaş makarna örneklerinin pişme özelliklerini belirlemek amacıyla, $20 \mathrm{~g}$ dolgusuz/dolgulu yaş makarna örneği $250 \mathrm{ml}$ saf su içinde 18 dakika pişirilmiştir. Pişirme suyunun süzülmesi için 2 dakika dinlendirilen pişmiş örnekler tartılarak pişmiş örnek ağırlığı belirlenmiştir. Pişmiş örnek ağırlığı değerinden, pişmemiş örnek ağırlığı çıkarılarak pişirme sonucu meydana gelen ağırlık artışı yüzde (\%) olarak tespit edilmiştir. Örneklerin hacim artışı değerlerinin belirlenmesi için, pişirilip süzülen makarna örnekleri içerisinde $150 \mathrm{ml}$ saf su bulunan 250 ml'lik ölçü silindirine konulmuş ve taşırdığı su miktarı saptanmıştır. Pişirmede kullanılan kuru örneklerin de aynı şekilde taşırdığı su miktarı belirlenmiş ve aradaki farktan hacim artışı yüzde (\%) olarak hesaplanmıştır (Oh ve ark., 1985). Örneklerin suya geçen kuru madde miktarının (SGMM) belirlenmesi için makarna örnekleri süzülerek alınmış, süzüntü suyu kurutma dolabında (Nüve FN-500, Ankara, Türkiye) $135^{\circ} \mathrm{C}^{\prime}$ de kurutularak, SGMM (\%) hesaplanmıştır (Kahveci ve Özkaya, 1989). Sıkılık analizi sadece dolgusuz makarna örneklerinde gerçekleştirilmiştir. Sıkılık analizinde AACC Standart Metotu (AACC, 2002) yöntemi esas alınmış ve tekstür analiz cihazı (TA-XT plus, Stable Mikrosistemleri, İngiltere) kullanılmıştır.

\section{Kimyasal analizler}

Yaş makarna örneklerinde bulunan fitik asit, $0.2 \mathrm{~N}$ hidroklorik asit çözeltisi ile ekstrakte edildikten sonra belli miktardaki demir III çözeltisi ile muamele edilip çöktürülmüştür. Serum kısmında kalan demir miktarı spektrofotometrik yolla belirlenerek, elde edilen sonuçlardan fitik asit miktarı hesaplanmıştır. Sonuçlar mg $100 \mathrm{~g}^{-1}$ cinsinden verilmiştir (Haug ve Lantzsch, 1983).

Yaş makarna örneklerinin toplam fenolik madde miktarı (TFMM), Folin-Ciocaltaeu Metodu kullanılarak kolorimetrik olarak tayin edilmiştir. Sonuçlar kuru madde esasına göre gram ekstrede 
mg gallik asite ( $\mathrm{mg} \mathrm{GAE} \mathrm{g}^{-1}$ ) eşdeğer olacak şekilde hesaplanmıştır (Slinkard ve Singelton, 1977; Gamez-Meza ve ark., 1999). Yaş makarnaların antioksidan aktivitelerinin (AA) belirlenmesinde DPPH (2-2-Diphenyl-2-picrylhydrazyl) metodu kullanılmıştır (Gyamfi ve ark., 1999; Beta ve ark., 2005). Analizlerde TFMM tayini için hazırlanan supernatant kullanılmıştır. Bu yöntem, serbest radikallerin DPPH vasıtasıyla, örnekte mevcut olan antioksidan maddeler tarafından elimine edilmesine dayanmaktadır. Analizin değerlendirilmesi aşağıdaki formüle göre gerçekleştirilmiştir.

$\%$ inhibisyon $=\left[\left(A b s_{\text {kontrol }}-A b s_{\text {örnek }}\right) / A b s_{\text {kontrol }}\right] \times 100$

\section{Mikrobiyolojik analizler}

Toplam mezofilik aerob bakteri $\left(30^{\circ} \mathrm{C}^{\prime}\right.$ de 48 saat inkübasyon) ve toplam psikrofilik aerob bakteri analizleri $\left(5^{\circ} \mathrm{C}^{\prime}\right.$ de 7 gün inkübasyon) için uygun dilüsyonlardan Plate Count Agar (PCA) kullanılarak yayma plak yöntemi ile ekim yapılmıştır, toplam koliform analizi $\left(37^{\circ} \mathrm{C}^{\prime}\right.$ de 24 saat inkübasyon) Violet Red Bile Agar (VRBA) kullanılarak, maya-küf analizi $\left(25^{\circ} \mathrm{C}^{\prime}\right.$ de 5 gün inkübasyon) PDA (Potato Dextrose Agar) besiyeri, \%10' luk tartarik asit ile pH 3.5'e ayarlanarak gerçekleştirilmiştir (Del Nobile ve ark., 2009). Koloni sayım sonuçları kob $\mathrm{g}^{-1}$ cinsinden ifade edilmiştir (Giannuzzi, 1998).

\section{Duyusal analizler}

Yaş makarnaların duyusal analizleri 25 panelist (25-55 yaş) tarafından gerçekleştirilmiştir. Panelistlerden, makarna örneklerini görünüş, tat, koku ve genel beğeni açısından değerlendirmeleri istenmiştir. Duyusal özellikler panelistler tarafından, 1-7 arasındaki skala (1:aşırı kötü, 7: mükemmel) kullanılarak değerlendirilmiştir.

\section{Istatistiki analizler}

İstatistiki analizlerde JMP istatistik programı, 10.0 versiyonu (SAS Institute Inc., Cary, NC, ABD) kullanılmıştır. Elde edilen veriler varyans analizine tabi tutularak, ana varyasyon kaynaklarının ortalamaları $p<0.05$ düzeyinde karşılaştırılmıştır.

\section{Araştırma Bulguları ve Tartışma}

Dolgusuz ve dolgulu yaş makarna örneklerinin depolama işlemi normal paketleme ve MAP olmak üzere iki şekilde gerçekleştirilmiştir. Normal paketleme yapılmış örnekler 10. günde bozulup tüketilemeyecek duruma geldiğinden deneme deseninde yer almamıştır. Depolama süreci boyunca, MAP uygulanmış örneklerin pişme özellikleri, sıkılık, fitik asit, TFMM, AA miktarları ile mikrobiyolojik ve duyusal özellikleri incelenmiştir.

Dolgusuz ve dolgulu yaş makarna örneklerinin pişme özellikleri

30 günlük depolama sırasında dolgusuz yaş makarna örneklerinin pişme özellikleri ve sıkılık değerleri Çizelge 2'de dolgulu yaş makarna örneklerinin pişme özellikleri Çizelge 3'de verilmiştir. Dolgusuz ve dolgulu yaş makarna örneklerinin pişme özellikleri incelendiğinde, BK kullanılarak üretilmiş yaş makarna örneklerinin ağırlık ve hacim artışı değerleri ile SGMM, BR kullanılarak hazırlanan yaş makarna örneklerinin aynı özelliklerinden daha yüksek olduğu belirlenmiştir (Çizelge 2 ve 3). BK ya da BR katkı oranının artması pişmiş dolgulu/dolgusuz yaş makarna örneklerinin ağırlık ve hacim artış değerlerinin yanı sıra SGMM'nı artırmıştır. Hacim artışının dolgulu yaş makarna örneklerinde \%20 katkı oranı dışında dolgusuz yaş makarna örneklerinden daha fazla olduğu belirlenmiştir. Yalnızca dolgusuz yaş makarna örneklerinde uygulanabilen tekstür analizi sonuçlarına göre, BR makarnalara daha sıkı özellik kazandırırken katkı oranının artması ve depolama süresi sıkılık değerinin azalmasına neden olmuştur. Pişmiş makarnaların sıkılık değerinde belirlenen bu azalıs depolama sırasında gluten mukavemetindeki kayıp ile ilişkilendirilebilir (Kaur ve ark., 2012). Her iki tip makarna örneği içinde depolama süresince SGMM de artış belirlenmiştir. Pişme kaybındaki bu artışın BK/BR ilavesi ile glutenin seyrelmesi ve $B R$ nin sahip olduğu çözünür protein miktarı ile ilgili olabileceği ifade edilmiştir (Tarzi ve ark., 2012; Pınarlı ve ark., 2004). 
Çizelge 2. Depolama sürecinde dolgusuz yaş makarna örneklerinin pişme ve sıkılık özellikleri Table 2. Cooking and firmness properties of unfilled fresh pasta samples during storage period

\begin{tabular}{|c|c|c|c|c|c|}
\hline $\begin{array}{l}\text { Faktör } \\
\text { Factor }\end{array}$ & $\mathrm{n}$ & $\begin{array}{l}\text { Ağırlık artışı (\%) } \\
\text { Weight increase } \\
(\%)\end{array}$ & $\begin{array}{l}\text { Hacim artışı (\%) } \\
\text { Volume increase } \\
(\%)\end{array}$ & $\begin{array}{l}\text { SGMM (\%) } \\
\text { Cooking loss } \\
(\%)\end{array}$ & $\begin{array}{l}\text { Sıkılık (g) } \\
\text { Firmness } \\
\text { (g) }\end{array}$ \\
\hline \multicolumn{6}{|l|}{ Katkı çeşidi } \\
\hline \multicolumn{6}{|l|}{ Additive type } \\
\hline $\begin{array}{l}\text { Buğday kepeği } \\
\text { Wheat bran }\end{array}$ & 40 & $99.95 \pm 7.76^{\mathrm{a}}$ & $82.02 \pm 15.30^{\mathrm{a}}$ & $4.41 \pm 0.63^{\mathrm{a}}$ & $414.33 \pm 36.43^{b}$ \\
\hline $\begin{array}{l}\text { Buğday ruşeymi } \\
\text { Wheat germ }\end{array}$ & 40 & $96.78 \pm 6.03^{b}$ & $77.68 \pm 6.28^{b}$ & $4.11 \pm 0.43^{b}$ & $460.69 \pm 7.59^{\mathrm{a}}$ \\
\hline \multicolumn{6}{|l|}{ Katkı oranı (\%) } \\
\hline \multicolumn{6}{|l|}{ Additive ratio (\%) } \\
\hline 0 & 16 & $89.73 \pm 1.80^{\mathrm{e}}$ & $67.62 \pm 1.57^{\mathrm{e}}$ & $3.67 \pm 0.06^{e}$ & $472.83 \pm 1.33^{a}$ \\
\hline 5 & 16 & $93.01 \pm 1.85^{d}$ & $73.55 \pm 1.47^{d}$ & $3.82 \pm 0.09^{d}$ & $445.93 \pm 17.38^{b}$ \\
\hline 10 & 16 & $97.67 \pm 2.44^{c}$ & $76.15 \pm 2.59^{c}$ & $4.10 \pm 0.22^{c}$ & $435.97 \pm 24.84^{c}$ \\
\hline 15 & 16 & $103.45 \pm 3.76^{b}$ & $84.44 \pm 2.09^{b}$ & $4.63 \pm 0.27^{b}$ & $425.17 \pm 29.96^{d}$ \\
\hline 20 & 16 & $107.95 \pm 2.42^{\mathrm{a}}$ & $97.48 \pm 12.53^{\mathrm{a}}$ & $5.07 \pm 0.30^{\mathrm{a}}$ & $407.65 \pm 44.32^{\mathrm{e}}$ \\
\hline \multicolumn{6}{|c|}{ Depolama süresi (gün) } \\
\hline \multicolumn{6}{|c|}{ Storage period (day) } \\
\hline 0 & 20 & $97.83 \pm 7.46^{\mathrm{a}}$ & $79.72 \pm 11.56^{\mathrm{a}}$ & $4.19 \pm 0.55^{c}$ & $439.76 \pm 34.83^{\mathrm{a}}$ \\
\hline 10 & 20 & $98.20 \pm 7.10^{\mathrm{a}}$ & $80.10 \pm 12.29^{a}$ & $4.22 \pm 0.58^{c}$ & $438.82 \pm 35.01^{\mathrm{a}}$ \\
\hline 20 & 20 & $98.53 \pm 6.93^{\mathrm{a}}$ & $79.56 \pm 11.85^{\mathrm{a}}$ & $4.28 \pm 0.56^{b}$ & $436.13 \pm 35.18^{b}$ \\
\hline 30 & 20 & $98.90 \pm 6.97^{\mathrm{a}}$ & $80.03 \pm 11.86^{a}$ & $4.33 \pm 0.55^{\mathrm{a}}$ & $435.33 \pm 35.04^{b}$ \\
\hline
\end{tabular}

Aynı harfle işaretlenmiş aynı sütundaki ortalamalar istatistiki olarak birbirinden farklı değildir (p<0.05). SGMM: Suya geçen madde miktarı

Means followed by the same letter within a column are not significantly different $(p<0.05)$.

Çizelge 3. Depolama sürecinde dolgulu yaş makarna örneklerinin pişme özellikleri

Table 3. Cooking properties of filled fresh pasta samples during storage period

\begin{tabular}{|c|c|c|c|c|}
\hline $\begin{array}{l}\text { Faktör } \\
\text { Factor }\end{array}$ & $\mathrm{n}$ & $\begin{array}{l}\text { Ağırlık artışı (\%) } \\
\text { Weight increase (\%) }\end{array}$ & $\begin{array}{l}\text { Hacim artışı (\%) } \\
\text { Volume increase (\%) }\end{array}$ & $\begin{array}{l}\text { SGMM (\%) } \\
\text { Cooking loss (\%) }\end{array}$ \\
\hline \multicolumn{5}{|l|}{ Katkı çeşidi } \\
\hline \multicolumn{5}{|l|}{ Additive type } \\
\hline $\begin{array}{l}\text { Buğday kepeği } \\
\text { Wheat bran }\end{array}$ & 40 & $106.30 \pm 8.85^{\mathrm{a}}$ & $82.27 \pm 7.60^{\mathrm{a}}$ & $4.44 \pm 0.53^{\mathrm{a}}$ \\
\hline Buğday ruşeymi & 40 & $104.15 \pm 7.80^{b}$ & $80.35 \pm 6.14^{b}$ & $4.15 \pm 0.34^{b}$ \\
\hline \multicolumn{5}{|l|}{ Katkı oranı (\%) } \\
\hline \multicolumn{5}{|l|}{ Additive ratio (\%) } \\
\hline 0 & 16 & $93.65 \pm 2.09^{\mathrm{e}}$ & $72.54 \pm 1.06^{\mathrm{e}}$ & $3.74 \pm 0.09^{e}$ \\
\hline 5 & 16 & $99.44 \pm 1.99^{d}$ & $76.55 \pm 2.89^{d}$ & $4.00 \pm 0.14^{d}$ \\
\hline 10 & 16 & $105.41 \pm 1.82^{c}$ & $80.77 \pm 2.73^{c}$ & $4.23 \pm 0.18^{c}$ \\
\hline 15 & 16 & $111.18 \pm 2.04^{b}$ & $85.10 \pm 1.46^{b}$ & $4.58 \pm 0.19^{b}$ \\
\hline 20 & 16 & $116.46 \pm 2.92^{\mathrm{a}}$ & $91.61 \pm 197^{\mathrm{a}}$ & $4.92 \pm 035^{a}$ \\
\hline \multicolumn{5}{|c|}{ Depolama süresi (gün) } \\
\hline \multicolumn{5}{|c|}{ Storage period (day) } \\
\hline 0 & 20 & $104.69 \pm 8.38^{\mathrm{a}}$ & $81.24 \pm 6.84^{\mathrm{a}}$ & $4.22 \pm 0.47^{c}$ \\
\hline 10 & 20 & $105.03 \pm 8.29^{\mathrm{a}}$ & $81.34 \pm 7.01^{\mathrm{a}}$ & $4.25 \pm 0.47^{c}$ \\
\hline 20 & 20 & $105.30 \pm 8.43^{\mathrm{a}}$ & $81.28 \pm 6.95^{\mathrm{a}}$ & $4.33 \pm 0.46^{b}$ \\
\hline 30 & 20 & $105.89 \pm 8.48^{\mathrm{a}}$ & $81.39 \pm 7.09^{\mathrm{a}}$ & $4.38 \pm 0.45^{\mathrm{a}}$ \\
\hline
\end{tabular}

Aynı harfle işaretlenmiş aynı sütundaki ortalamalar istatistiki olarak birbirinden farklı değildir ( $p<0.05)$. SGMM: Suya geçen madde miktarı

Means followed by the same letter within a column are not significantly different $(p<0.05)$.

Dolgusuz ve dolgulu yaş makarna örneklerinin fitik asit, TFMM ve AA değerleri

30 günlük depolama sırasında dolgusuz ve dolgulu yaş makarna örneklerinin fitik asit, TFMM ve AA değeri sırasıyla Çizelge 4 ve Çizelge 5 'de verilmiştir. Hububatta fitik asitin en yüksek birikim bölgelerinden birinin BK ile ayrılan aleuron tabakası olması (Ogawa ve ark. 1979; Reddy ve ark., 1982; Bilgiçli, 2002), katkı çeşitlerinden BK kullanılarak üretilen dolgusuz ve dolgulu yaş 
makarna örneklerinin fitik asit içeriklerinin BR kullanılarak üretilen yaş makarnalardan daha yüksek bulunması ile sonuçlanmıştır (Çizelge 4 ve 5). Hububat ve baklagil tanelerinin kepek ve ruşeym kısımlarında yoğunlaşmış olan fitik asit (Bilgiçli, 2002) BK ve BR'nin artan oranlarda makarna formülasyonunda kulllanılmasıyla yaş makarna örneklerinin fitik asit içeriğini artırmıştır. Depolama ile dolgusuz ve dolgulu yaş makarnaların fitik asit içeriği azalmıştır. Yaş makarnalara uygulanan pastörizasyon işleminin sonucunda fitazın tamamen inaktif hale gelmemiş olması makarnanın depolanması esnasında fitik asitin bir miktar azalmasına neden olmuş olabilir. Soya fasulyesinin $5^{\circ} \mathrm{C}$ ve $30^{\circ} \mathrm{C}$ de depolanması sırasında fitik asitte azalma olduğu Buckle (1985) tarafından bildirilmiştir. Sievwright ve Shipe (1986) benzer şekilde ıslatılmış ve pişirilmiş siyah fasülyelerde (Phaseolus vulgaris) depolama ile birlikte fitik asit içeriğinin azaldığını belirtmişlerdir.

Formülasyonunda BR kullanılan dolgusuz ve dolgulu yaş makarna örneklerinde $A A$ değerlerinin BK kullanılanlardan daha yüksek olduğu belirlenmiştir (Çizelge 4 ve 5). Her iki katkı çeşidinin artan oranlarda kullanılması ile birlikte TFMM ve AA değerleri artmış ve en yüksek değerlere \%20 ilave oranında ulaşılmıştır. Genel olarak yaş makarnaların TFMM depolama süresi arttıkça sayısal olarak azalma göstermiş ancak bu azalma sadece dolgulu makarnalarda depolamanın 30. gününde istatistiki olarak önemli $(p<0.05)$ bulunmuştur. Depolama süresince hem dolgulu hem de dolgusuz makarnaların AA değerlerinde önemli düzeyde $(p<0.05)$ azalma meydana gelmiştir. Depolama sırasındaki AA deki azalmanın nedeni, antioksidan bileşenlerin depolanma sırasında uygun koşullar altında oksidasyonuna bağlanabilir. Düşük depolama sıcaklığında TFMM ve AA değerlerindeki azalışın daha yavaş gerçekleştiği literatürde rapor edilmektedir (Cao ve ark., 2006). Dar ve ark. (2016), buğday, yulaf ve pirinç kepeklerini farklı oranlarda kullanarak ekstrüde atıştırmalıklar üretmişler ve depolama sürecinde örneklerin $A A$ ve TFMM nın azaldığını bildirmişlerdir. Camire ve ve ark. (2005), ekstrüde mısırda lipit oksidasyonu üzerinde çalışırken fenolik bileşenlerin depolama sırasında kaybolduğunu rapor edilmiştir.

Çizelge 4. Depolama sürecinde dolgusuz yaş makarna örneklerinin fitik asit, TFMM ve AA değerleri

Table 4. Phytic acid, TPC and AA values of unfilled fresh pasta samples during storage period

\begin{tabular}{|c|c|c|c|c|}
\hline $\begin{array}{l}\text { Faktör } \\
\text { Factor }\end{array}$ & $\mathrm{n}$ & 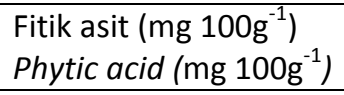 & $\begin{array}{l}\left.\text { TFMM (mg GAE g }{ }^{-1}\right) \\
T P C\left(m g G A E g^{-1}\right)\end{array}$ & $\begin{array}{l}\mathrm{AA}(\%) \\
A A(\%)\end{array}$ \\
\hline \multicolumn{5}{|l|}{ Katkı çeşidi } \\
\hline \multicolumn{5}{|l|}{ Additive type } \\
\hline $\begin{array}{l}\text { Buğday kepeği } \\
\text { Wheat bran }\end{array}$ & 40 & $391.31 \pm 185.31^{\mathrm{a}}$ & $0.59 \pm 0.08^{a}$ & $23.06 \pm 5.83^{b}$ \\
\hline $\begin{array}{l}\text { Buğday ruşeymi } \\
\text { Wheat germ }\end{array}$ & 40 & $354.88 \pm 161.39^{b}$ & $0.62 \pm 0.09^{\mathrm{a}}$ & $26.20 \pm 8.68^{\mathrm{a}}$ \\
\hline \multicolumn{5}{|l|}{ Katkı oranı (\%) } \\
\hline \multicolumn{5}{|l|}{ Additive ratio (\%) } \\
\hline 0 & 16 & $128.92 \pm 2.72^{\mathrm{e}}$ & $0.51 \pm 0.04^{d}$ & $14.92 \pm 1.21^{\mathrm{e}}$ \\
\hline 5 & 16 & $253.31 \pm 9.94^{d}$ & $0.56 \pm 0.04^{c}$ & $19.57 \pm 1.28^{d}$ \\
\hline 10 & 16 & $374.27 \pm 22.46^{c}$ & $0.61 \pm 0.05^{b}$ & $23.89 \pm 1.08^{c}$ \\
\hline 15 & 16 & $483.46 \pm 24.45^{b}$ & $0.66 \pm 0.06^{a}$ & $29.60 \pm 2.88^{b}$ \\
\hline 20 & 16 & $625.52 \pm 35.46^{\mathrm{a}}$ & $0.69 \pm 0.04^{a}$ & $35.18 \pm 4.11^{a}$ \\
\hline \multicolumn{5}{|c|}{ Depolama süresi (gün) } \\
\hline \multicolumn{5}{|c|}{ Storage period (day) } \\
\hline 0 & 20 & $376.04 \pm 175.99^{a}$ & $0.63 \pm 0.08^{a}$ & $25.78 \pm 7.29^{a}$ \\
\hline 10 & 20 & $374.32 \pm 175.21^{\mathrm{ab}}$ & $0.61 \pm 0.08^{a}$ & $25.10 \pm 7.63^{b}$ \\
\hline 20 & 20 & $371.68 \pm 173.58^{b c}$ & $0.60 \pm 0.08^{a}$ & $24.36 \pm 7.51^{c}$ \\
\hline 30 & 20 & $370.33 \pm 173.35^{c}$ & $0.58 \pm 0.08^{a}$ & $23.29 \pm 7.57^{d}$ \\
\hline
\end{tabular}

Aynı harfle işaretlenmiş aynı sütundaki ortalamalar istatistiki olarak birbirinden farklı değildir ( $p<0.05)$. Sonuçlar kuru madde üzerinden verilmiştir. TFMM: Toplam fenolik madde miktarı, AA: Antioksidan aktivite.

Means followed by the same letter within a column are not significantly different $(p<0.05)$. Results are based on dry matter. TPC: Total phenolic content, AA: Antioxidant activity. 
Dolgusuz ve dolgulu yaş makarna örneklerinin mikrobiyolojik özellikleri

MAP ve normal paketleme yöntemleriyle ambalajlandıktan sonra 30 gün süre ile depolanmaları planlanan makarna örneklerinden normal atmosfer koşullarında paketlenmiş yaş makarna örneklerinde depolamanın 7. gününden itibaren küf gelişimi gözlemlenmiştir, örneklerin mikrobiyolojik açıdan tüketilemeyecek hale geldiği belirlenmiş ve bu örneklerin depolanmasına 10. gün analizlerinin ardından son verilmiştir. Türk Gıda Kodeksi, Mikrobiyolojik Kriterler Tebliği'nde dondurulmuş ve dondurulmamış, pişirmeye hazır, erişte, pizza, börek mantı gibi ürünler için çeşitli mikrobiyolojik, fiziksel ve kimyasal özellikler belirtilmiştir. Mikrobiyolojik özellik olarak toplam aerobik mezofilik bakteri için limit değerler örnekleme planı dahilinde $10^{4}-10^{5} \mathrm{kob} / \mathrm{g}$ olarak belirlenmiştir (Anonim, 2003). MAP uygulanmış yaş makarna örnekleri, mezofilik ve psikrofilik mikroorganizmaların gelişimi açısından değerlendirildiğinde, her iki katkı çeşidi ve dolgu materyali açısından depolamanın 30. gününe kadar mikrobiyal yükün belirlenen sınırların altında kaldığı görülmüştür. Maya/küf gelişiminde ise dolgu materyali içeren ve katkı oranı \%20 olan örnekler 20. günden itibaren belirlenen sınırın üstüne çıkmıştır. Dolgusuz örnekler ise 30. gününe kadar belirlenen sınırların altında kalmışlardır. Beklenildiği gibi pastörizasyon ve MAP, örneklerde mikrobiyal yükü ve gelişimi azaltmayı başarmıştır. BK ve BR'nin \%20 ilavesiyle üretilen dolgulu yaş makarna örneklerinde depolamanın 20. gününden itibaren mikrobiyal gelişim hızlanmıştır. Mayalar aerobik mikroorganizmalar olmalarına rağmen MAP kullanılarak hazırlanan paket içerisinde $\% 60$ ve daha yüksek $\mathrm{CO}_{2}$ konsantrasyonuna kadar canlı kalabilmektedirler (Bogadte, 1979; Abellana ve ark., 2000).

Çizelge 5. Depolama sürecinde dolgulu yaş makarna örneklerinin fitik asit, TFMM ve AA değerleri

Table 5. Phytic acid, TPC and AA values of unfilled fresh pasta samples during storage period

\begin{tabular}{|c|c|c|c|c|}
\hline $\begin{array}{l}\text { Faktör } \\
\text { Factor }\end{array}$ & $\mathrm{n}$ & 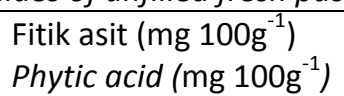 & $\begin{array}{l}\left.\text { TFMM (mg GAE g }{ }^{-1}\right) \\
T P C\left(m g G A E g^{-1}\right)\end{array}$ & $\begin{array}{l}\mathrm{AA}(\%) \\
A A(\%)\end{array}$ \\
\hline \multicolumn{5}{|l|}{ Katkı çeşidi } \\
\hline \multicolumn{5}{|l|}{ Aditive type } \\
\hline $\begin{array}{l}\text { Buğday kepeği } \\
\text { Wheat bran }\end{array}$ & 40 & $381.35 \pm 184.70^{a}$ & $0.63 \pm 0.08^{\mathrm{a}}$ & $24.35 \pm 5.81^{b}$ \\
\hline $\begin{array}{l}\text { Buğday ruşeymi } \\
\text { Wheat germ }\end{array}$ & 40 & $347.07 \pm 161.34^{b}$ & $0.65 \pm 0.09^{a}$ & $27.31 \pm 7.77^{\mathrm{a}}$ \\
\hline \multicolumn{5}{|l|}{ Katkı oranı (\%) } \\
\hline \multicolumn{5}{|l|}{ Aditive ratio (\%) } \\
\hline 0 & 16 & $120.34 \pm 2.23^{\mathrm{e}}$ & $0.53 \pm 0.05^{e}$ & $16.98 \pm 2.23^{\mathrm{e}}$ \\
\hline 5 & 16 & $244.20 \pm 9.42^{d}$ & $0.59 \pm 0.04^{d}$ & $20.92 \pm 1.04^{d}$ \\
\hline 10 & 16 & $363.66 \pm 21.73^{c}$ & $0.63 \pm 0.04^{c}$ & $25.44 \pm 1.18^{c}$ \\
\hline 15 & 16 & $478.30 \pm 21.57^{b}$ & $0.69 \pm 0.04^{b}$ & $29.72 \pm 3.16^{b}$ \\
\hline 20 & 16 & $614.54 \pm 35.23^{\mathrm{a}}$ & $0.75 \pm 0.05^{\mathrm{a}}$ & $36.11 \pm 3.03^{a}$ \\
\hline \multicolumn{5}{|c|}{ Depolama süresi (gün) } \\
\hline \multicolumn{5}{|c|}{ Storage period (day) } \\
\hline 0 & 20 & $367.51 \pm 176.00^{a}$ & $0.66 \pm 0.09^{\mathrm{a}}$ & $27.01 \pm 7.05^{a}$ \\
\hline 10 & 20 & $364.69 \pm 174.15^{\mathrm{ab}}$ & $0.64 \pm 0.09^{\mathrm{a}}$ & $26.20 \pm 6.90^{b}$ \\
\hline 20 & 20 & $362.56 \pm 173.67^{b}$ & $0.63 \pm 0.09^{a}$ & $25.46 \pm 6.97^{c}$ \\
\hline 30 & 20 & $362.07 \pm 173.13^{b}$ & $0.62 \pm 0.09^{b}$ & $24.65 \pm 6.93^{d}$ \\
\hline
\end{tabular}

Aynı harfle işaretlenmiş aynı sütundaki ortalamalar istatistiki olarak birbirinden farklı değildir ( $<<0.05)$. Sonuçlar kuru madde üzerinden verilmiştir. TFMM: Toplam fenolik madde miktarı, AA: Antioksidan aktivite.

Means followed by the same letter within a column are not significantly different $(p<0.05)$. Results are based on dry matter TPC: Total phenolic content. AA: Antioxidant activity.

Sanguinetti ve ark. (2011), çalışmalarında peynir dolgulu yaş makarna örneklerinde MAP uygulamasının normal paketleme işlemine göre, örneklerin raf ömrünü 5 kat artırdığını ifade etmişlerdir. Sanguinetti ve ark. (2015), yaptıkları bir başka çalışmada ise yaş makarna örneklerini $91^{\circ} \mathrm{C}$ 'de $9 \mathrm{dk}$ süreyle pastörize etmişler, pastörizasyon işleminin toplam bakteri sayısında 
azalma sağladığını belirlemişlerdir. Ayrıca aynı çalışmada, depolamanın 14. gününden sonra tüm örneklerin toplam bakteri sayılarında artış olduğunu bildirmişlerdir. Mevcut çalışmada, dolgusuz ve dolgulu yaş makarna örnekleri aynı pastörizasyon normu kullanılarak pastörize edilmişlerdir. Ayrıca bu çalışmada kullanılan BK ve
BR nin makarna üretiminde kullanılmadan önce stabilize edilerek mikrobiyal yüklerinin düşürülmüş olması ve yukarıda verilen pastörizasyon normlarına ilaveten, MAP uygulamasının yapılması, mikrobiyal kaliteyi geliştirmiştir.
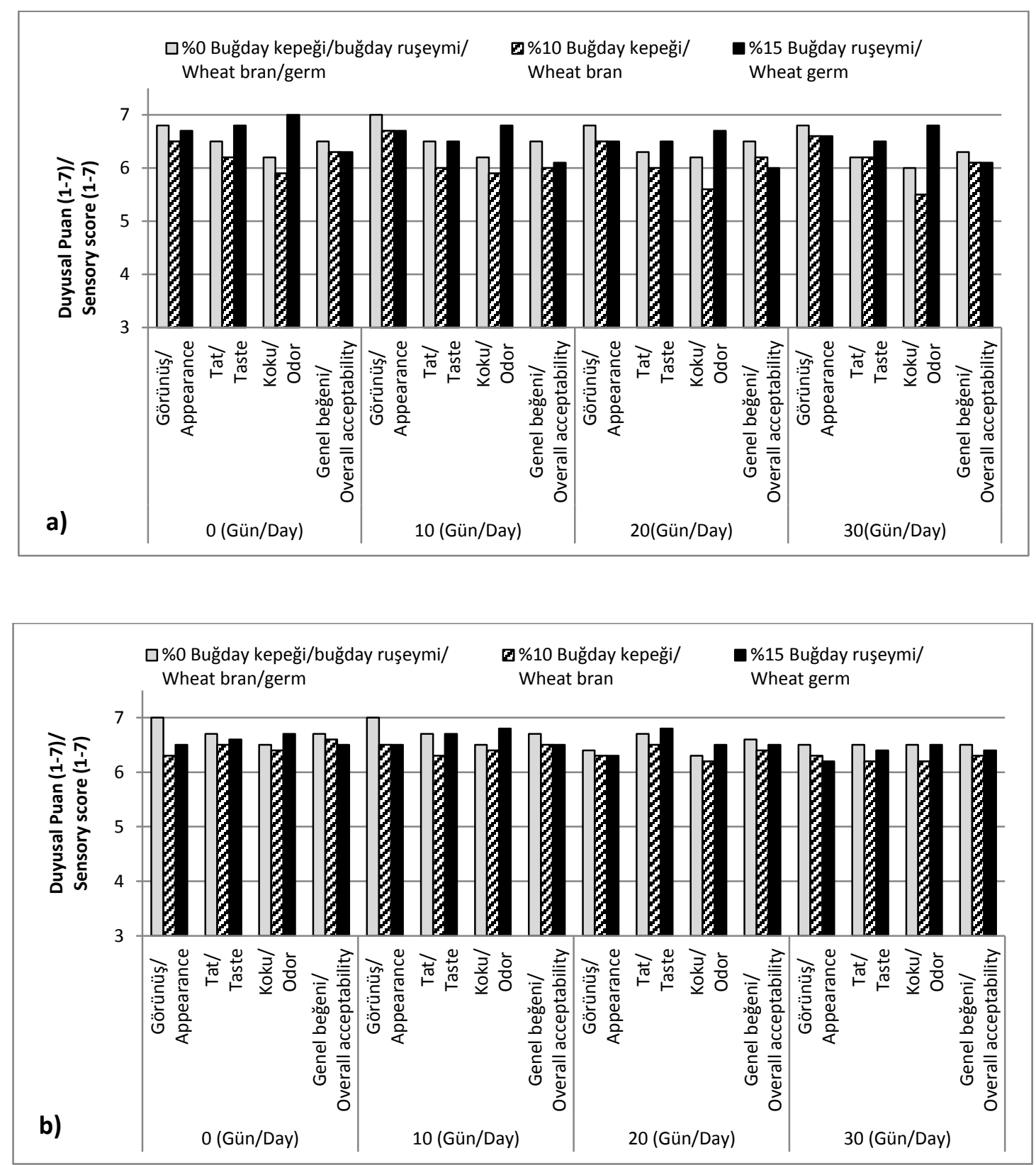

Şekil 1. Depolama süresince dolgusuz ve dolgulu yaş makarna örneklerinin duyusal analiz sonuçları (dolgusuz (a) ve dolgulu (b) yaş makarna)

Figure 1.Sensory scores of unfilled and filled fresh pasta samples during storage period (unfilled (a) and filled (b) fresh pasta)

Dolgusuz ve dolgulu yaş makarna örneklerinin duyusal özellikleri

Çalışmanın ilk gününde yapılan duyusal değerlendirme sonucunda yaş makarna örneklerinden, en yüksek duyusal değerlendirme puanı alan dolgusuz ve dolgulu yaş makarna örneklerinden "katkısız", “\%10 BK katkılı” ve “\%15 BR katkılı" olanlar, 30 günlük depolama süresi boyunca her 10 günde bir duyusal analize tabi tutulmuşlardır. Sonuçlar Şekil 1'de özetlenmiştir. 
Dolgusuz örneklerde depolama süresine bağlı olarak görünüş değerlerinde anlamlı bir değişim gözlenmezken dolgulu örneklerde 20. günden itibaren katkısız ve \%15 ruşeym ilaveli yaş makarna örneğinin görünüş puanlarında hafif bir azalma söz konusu olmuştur. Dolgusuz ve dolgulu yaş makarna örnekleri içinde \%15 ruşeym ilaveli olanlar, 30 günlük depolama süresi boyunca katkısız örneğe eşdeğer ya da daha yüksek tat puanlarını muhafaza etmiştir. Depolamanın 20. gününden sonra koku puanlarında hafif bir azalma belirlenmiştir. Ancak bu azalmalar çok düşük düzeyde kaldığından, genel olarak 30 günlük depolama süresi boyunca dolgusuz ve dolgulu yaş makarnaların duyusal kalitesini muhafaza ettiği söylenebilir. Sonuçlar genel beğeni değeri açısından değerlendirildiğinde; hem dolgulu hem de dolgusuz örneklerin genel beğeni puanlarında depolama süresine bağlı olarak anlamlı bir değişim gözlenmemiştir.

\section{Sonuçlar}

Dolgusuz ve dolgulu makarna örneklerinde depolamaya bağı olarak ağırlık artışı ve hacim artışı değerlerinde bir değişim belirlenmezken, SGMM' ında depolama süresine bağlı bir artış gerçekleşmiştir. Depolama süresi her iki yaş makarna tipinde de AA ve fitik asit miktarlarında azalmaya neden olmuştur. Normal paketlenmiş yaş makarna örnekleri 10. günde mikrobiyolojik olarak tüketilmeyecek hale gelmiştir. MAP uygulanmış yaş makarna örnekleri, mezofilik ve psikrofilik mikroorganizmaların gelişimi açısından değerlendirildiğinde, her iki katkı çeşidi ve dolgu materyali açısından depolamanın 30. gününe kadar Türk Gıda Kodeksi, Mikrobiyolojik Kriterler Tebliği'inde belirtilen sınırların altında kaldığı görülmüştür. Maya/küf gelişiminde ise dolgu materyali içeren ve katkı oranı \%20 olan örnekler 20. günden itibaren belirlenen sınırın üstüne çıkmıştır. Depolamaya bağlı olarak takip edilen duyusal analiz sonuçlarına göre, örneklerin genel olarak duyusal kalitesini muhafaza ettiği söylenebilir.

\section{Ekler}

$\mathrm{Bu}$ çalışma, Tekmile CANKURTARAN'nın "Dolgusuz ve dolgulu Yaş Makarna Üretiminde Buğday Kepeği ve Buğday Ruşeymi Katkısının Bazı Kalite Özellikleri Üzerine Etkisi" başlıklı yüksek lisans tezinden alınmış olup, ayrıca "International Conference on Agriculture, Forest, Food Sciences and Technologies (IAMPCON-2017)'de poster olarak sunulmuş ve özet olarak basılmıştır.

\section{Kaynaklar}

AACC, (2002). Approved methods of the AACC, American Association of Cereal Chemists, Saint Paul, MN.

Abellana, M., Sanchis, V., Ramos, A. J., \& Nielsen, P. V. (2000). Effect of modified atmosphere packaging and water activity on growth of Eurotium amstelodami, $E$. chevalieri and $E$. herbariorum on a sponge cake analogue. Journal of Applied Microbiology, 88, 606616.

Alamprese, C., Casiraghı, E., \& Rossi, M. (2008). Structural and cooking properties of fresh egg pasta as function of pasteurization treatment intensity. Journal of Food Engineering, 89, 1-7.

Alamprese, C., lamettı, S., Rossı, M., \& Bergonzı, D. (2005). Role of pasteurization heat treatments on rheological nd protein structural characteristics of fresh egg pasta. European Food Research and Technology, 221, 759-767.

Anonim, (2003). Mantı-Dondurulmuş 12980 Türk Standardı. Türk Standartları.

Apprich, S., Tirpanalan, Ö., Hell, J., Reisinger, M., Böhmdorfer, S., Siebenhandl-Ehn, S., Novalin, S., \& Kneifel, W. (2014). Wheat bran-based biorefinery 2: valorization of products. LWT-Food Science and Technology, 56, 222-231.

Aravind, N., Sissons, M., Egan, N., \& Fellows, C. (2012). Effects of insoluble dietary fiber addition on technological, sensory and structural properties of durum wheat spaghetti. Food Chemistry, 130, 299309.

Arrigoni, E., Jorger, F., Kolloffel, B., Roulet, I., Herensperger, M., \& Meile,L. (2002). In vitro fermentability of a commercial wheat germ preparation and its impact on the growth of bifidobacteria. Food Research International, 35(5), 475-481.

Beta, T., Nam, S., Dexter, J. E., \& Sapirstein, H. D. (2005). Phenolic content and antioxidant activity of pearled wheat and roller-milled fractions. Cereal Chemistry, 82:390-393.

Bilgiçli N., \& Levent H. (2013). Improvement of nutritional properties of cake with wheat germ and resistant starch. Journal of Food and Nutrition Research, 52(4), 210-218.

Bilgiçli, N. (2002). Fitik asitin beslenme açısından önemi ve fitik asit miktarı düşürülmüş gıda üretim metotları. 
Selçuk Üniversitesi Ziraat Fakültesi Dergisi, 16(30), 79-83.

Bogadte, B. (1979). Use of $\mathrm{CO}_{2}$ in packaging foods. Ernahrungs-Wirtschaft, 7(8), 33-43.

Buckle, K.A. (1985). Reduction in phytic acid levels in soybeans during tempeh production, storage and frying. Journal of Food Science, 50(1), 260-263.

Cao, S.F., Zheng, Y.H., Yang, Z.F., Li, N., Ma, S.J., Tang, S.S., \& Zhang, J.H. (2006). Effects of storage temperature on antioxidant composition and antioxidant activity of loquat fruit. In II International Symposium on Loquat 750, pp:471-476.

Camire, M. E., Dougherty, M. P., \& Briggs, J. L. (2005). Antioxidant-rich foods retard lipid oxidation in extruded corn. Cereal chemistry, 82(6), 666-670.

Castelvetri F. (1991). II confezionamento in atmosfera modificata dei prodotti di pasta freschi. Tecnica Molitoria 30(10):875-879.

Daniels, J.A., Krishnamurthi, R., \& Rizvi, S.S.H. (1985). A review of effects of carbon dioxide on microbial growth and food quality. Journal of Food Protection, 48, 532-537.

Dar, B.N., Sharma, S., \& Nayik, G.A. (2016). Effect of storage period on physiochemical, total phenolic content and antioxidant properties of bran enriched snacks. Journal of Food Measurement and Characterization, 10(4), 755-761.

de Cindio, B., Celot, F., Migliori, M., \& Pollini, C.M. (2001). A simple rheological model to predict filled fresh pasta failure during heat treatment. Journal of Food Engineering, 48(1), 7-18.

Del Nobile, M.A., Di Benedetto, N., Suriano, N., Conte, A., Lamacchia, C. \& Sinigaglia, M. (2009). Use of natural compounds to improve the microbial stability of Amaranth-based homemade fresh pasta. Food Microbiology, 26, 151-156.

Demir, M.K., \& Elgün, A. (2014). Comparison of autoclave, microwave, IR and UV-C stabilization of whole wheat flour branny fractions upon the nutritional properties of whole wheat bread. Journal of Food Science and Technology, 51(1), 59-66.

Gamez-Meza, N., Noriega-Rodriguez, J.A., Medina-Juarez, L.A., Ortega Garcia, J., Cazarez-Casanova, R., \& Angulo-Guerrero, O. (1999.) Antioxidant activity in soybean oil of extracts from thompson grape bagasse. Journal of the American Oil Chemists Society (JAOCS), 76,1445-1447.

Ge, Y., Sun, A., Ni, Y., \& Cai, T. (2001). Study and development of a defatted wheat germ nutritive noodle. European Food Research and Technology, 212(3),344-348.

Giannuzzi, L. (1998). Mathematical modeling of microbial growth in fresh filled pasta stored at different temperatures. Journal of Food Processing Preservation, 22,433-447.

Gómez, M., González, J., \& Oliete, B. (2012). Effect of extruded wheat germ on dough rheology and bread quality. Food and Bioprocess Technology, 5(6), 24092418.

Gyamfi, M.A., Yonamine, M., \& Aniya, Y. (1999). Free radical scavenging action of medical herbs from ghane: Thonningia sanguinea on experimentally-induced liver injuries. General Pharma, 32 (6), 661-667.
Haug, W., \& Lantzsch, H.J. (1983). Sensitive method for the rapid determination of phytate in cereals and cereals product. Journal of the Science of Food and Agriculture, 34,1423-1426.

Javed, M.M., Zahoor, S., Shafaat, S., Mehmooda, I., Gul, A., Rasheed, H., Bukhari, S.A. I., \& Aftab, M.N. (2012). Wheat bran as a brown gold: nutritious value and its biotechnological applications. African Journal of Microbiology Research, 6,724-733.

Kahveci, B., \& Özkaya, H., (1989). Farklı oranlarda ekmeklik buğday katılmış bazı durum çeşitlerinin makarnalık kalitesi üzerine araştırmalar. Doğa, 13 (3), 10331047.

Kaur, G., Sharma, S., Nagi, H.P.S., \& Dar, B.N. (2012). Functional properties of pasta enriched with variable cereal brans. Journal of Food Science and Technology, 49, 467-474.

Majzoobi, M., Farhoodi, S., Farahnaky, A., Taghipour, \& M.J. (2012). Properties of dough and flat bread containing wheat germ. Journal of Agricultural Science and Technology, 14, 1053-1065.

Northolt, M.D., \& Bullerman, L.B. (1982). Prevention of mold growth and toxin production through control of environmental conditions. Journal of Food Protection, 45(6), 519-526.

Ogawa, M., Tanaka, K., \& Kasai, Z. (1979). Phytic acid formation in dissected ripening rice grains. Agricultural Biological Chemistry 43(10), 2211-2213.

Oh, N.H., Seib, P.A., Chung, D.S., \& Deyoe, C.W. (1985). Noodle. III. Effects of processing variables on the quality of dry noodle. Cereal Chemistry, 62 (6), 437440.

Pınarlı, İ., ỉbanoğlu, Ş., \& Öner, M.D. (2004). Effect of storage on the selected properties of macaroni enriched with wheat germ. Journal of Food Engineering, 64, 249-256.

Rebolleda, S., Beltraan, S., Sanz, M.T., Gonzalez-Sanjose, M.L., \& Solaesa, A.G. (2013). Extraction of alkylresorcinols from wheat bran with supercritical $\mathrm{CO}_{2}$. Journal of Food Engineering, 119, 814-821.

Reddy, N.R., Sathe, S.K., \& Salunke, D.H. (1982). Phytates in legumes and cereals. Advances in Food Research, 28, 1-92.

Reisinger, M., Tirpanalan, Ö., Prückler, M., Huber, F., Kneifel, W., \& Novalin, S. (2013). Wheat bran biorefinery - A detailed investigation on hydrothermal and enzymatic treatment. Bioresource Technology, 144, 179-185.

Sanguinetti, A.M., Del Caro, A., Mangia, N.P., Secchi, N., Catzeddu, P., \& Piga, A. (2011). Quality changes of fresh filled pasta during storage: Influence of modified atmosphere packaging on microbial growth and sensory properties. Food Science and Technology International, 17, 23-29.

Sanguinetti, A.M., Secchi, N., Del Caro, A., Fadda, C., Fenı, P.A.M., Catzeddu, P., \& Piga, A. (2015). Gluten-free fresh filled pasta: the effects of xanthan and guar gum on changes in quality parameters after pasteurisation and during storage. LWT-Food Science and Technolgy, 64, 678-684.

Sievwright, C.A., Shipe, \& W.F. (1986). Effect of storage conditions and chemical treatments on firmness, in vitro protein digestibility, condensed tannins, phytic 
acid and divalent cations of cooked black beans (Phaseolus vulgaris). Journal of Food Science, 51(4), 982-987.

Slinkard, K., \& Singelton, V.L. (1977). Total phenolic analysis, automation and comparison with manual methods. American Journal of Enology and Viticulture, 28, 49-55.

Sobota, A., Rzedzicki, Z., Zarzycki, P., \& Kuzawinska, E. (2015). Application of common wheat bran for the industrial production of high-fiber pasta. International Journal of Food Science and Technology, 50, 111-119.

Tarzi, B.G., Valeh, S., \& Mehrdad, G. (2012). Quality evaluation of pasta enriched with heated and unheated wheat germ during storage. Advances in Environmental Biology, 1700-1708.

Tazrart, K., Lamacchia, C., Zaidi, F., \& Haros, M. (2016). Nutrient composition and in vitro digestibility of fresh pasta enriched with Vicia faba. Journal of Food Composition and Analysis, 47, 8-15.
Wojtowicz, A., \& Moscicki, L. (2011). Effect of wheat bran addition and screw speed on microstructure and textural characteristics of common wheat precooked pasta-like products. Polish Journal of Food and Nutrition Science, 61, 101-107.

Zardetto, S., \& Dalla Rosa, M. (2007). Effect of heat treatment on the microbiology and quality of fresh filled pasta. In New Issues in Food Policy, Control and Research (P. Riley, ed.) pp. 45-66. Nova Science Publishers, Inc, New York, NY.

Zardetto, S., Di Fresco, S., \& Dalla Rosa, M. (2002), Effetto di trattamenti termici sulle caratteristiche chimicofisiche della pasta. Tecnica Molitoria, 2, 113-130.

Zhokhov, S.S., Broberg, A., Kenne, L., \& Jastrebova, J. (2010). Content of antioxidant hydroquinones substituted by beta-1, 6-linked oligosaccharides in wheat milled fractions, flours andbreads. Food Chemistry, 121(3), 645-652.

Zuliani, R. (1998). Studio sulle capacita` di reidratazione di pasta farcita. Degree Thesis, University of Udine, Italy, p. 80. 